EISSN: 2706 -7947 ISSN: 2077- 4613

DOI: 10.36632/mejas/2021.11.1.17

Journal homepage: www.curresweb.com

Pages: 237-244

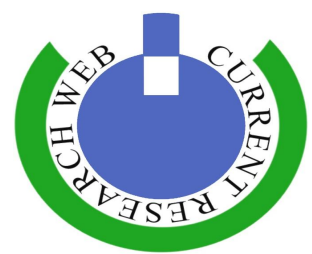

\title{
Rural-urban differentials in selected socio-demographic characteristics of Bangladeshi population
}

\author{
Rabiul Islam ${ }^{1}$ and K.M. Mustafizur Rahman² \\ ${ }^{1}$ Department of Social Work, University of Rajshahi, Bangladesh.E-mail: rabiul.islam@ru.ac.bd \\ ${ }^{2}$ Department of Population Science, Jatiya Kabi Kazi Nazrul Islam University Trishal, \\ Mymensingh, Bangladesh.E-mail: nishan_hrd@yahoo.com
}

Received: 19 January $2021 \quad$ Accepted: 26 February $2021 \quad$ Published: 10 March 2021

\begin{abstract}
Differences is socio-demographic and economic sectors remain are somehow considered as the stumbling block to the sustainable development. This paper makes an attempt to explore the situation of rural-urban differentials to find a clear picture in formulating new policies and programmes regarding overall socioeconomic development of Bangladesh. The data of this study was mainly collected from the Report on Bangladesh Sample Vital Statistics (SVRS) of different years published by Bangladesh Bureau of Statistics (BBS). It is found that, despite government initiatives to reduce rural-urban disparity in the context of development, the inequality between rural and urban areas persists and challenges continue to evolve. The results of this study should contribute to the creation of innovative and effective policies and programmes that can improve the status of rural-urban differentials in Bangladesh. Findings of this study need to be scientifically utilised in developing suitable programmes addressing the causes of rural-urban differentials in Bangladesh. Otherwise, the aim of comprehensive and sustainable development may remain elusive.
\end{abstract}

Keywords: Rural, urban, inequality, correlation, demography, Bangladesh.

\section{Introduction}

Bangladesh is one of the densely populated countries in the world where most of its population are still living in rural areas. About 77 percent population of Bangladesh live in rural areas while 23 percent in urban areas (BBS, 2015). The country has made some remarkable progresses in socioeconomic and demographic sectors over the last few decades. These progresses have already been reflected in the achievement of different targets of millennium development goals (MDGs) and committed to achieve the sustainable development goals (SDGs) within the specific time period. The country has also advanced in the area of social indicators, despite one in every three people living below the poverty line (Rahman, Hoque \&Titumir, 2016). It is assumed that with some of other variables, the development of Bangladesh is slowed down due to rural-urban inequalities. Generally in most cases, the urban areas experienced high levels of growth and development while rural areas have experienced little change (Heyns, 2005).In Bangladesh, rural-urban disparity in terms of per capita income, consumption, education, healthcare facilities, and physical infrastructure is an important developmental issue. Still to what extent the rural-urban divide has weakened and whether rural-urban inequality has declined or increased are still ardently debated issues.

Most of the countrymen are consider the rural life as undesirable compared to urban life. Opportunities in various sectors like education, health, employment etc. are higher in urban areas than the rural. There are differences between urban and rural education, including differences in quality (Giroux, Jah \& Eloundou-Enyegue, 2010; Agrawal, 2014), early education opportunities (Miller \&Votruba-Drzal, 2013), and post-secondary outcomes including participation in higher education (Byun, Meece \& Irvin, 2012; Provasnik, Kewal-Remani, Coleman, Gilbertson, Gerring, \& Xie, 2007;

Corresponding Author: K.M. Mustafizur Rahman, 2Department of Population Science, Jatiya Kabi Kazi Nazrul Islam University Trishal, Mymensingh, Bangladesh.

E-mail: nishan_hrd@yahoo.com 
Koricick, 2014; Chankseliani, 2013; MacTavish \& Salamon, 2006; McIlveen, Morgan \& Bimrose, 2012), as well as differences in parents' level of education (Iannelli, 2002).The prevalence of poverty is often found in higher levels in rural areas compared to urban (Tickamyer \& Duncan, 1990; Zichy, 2000; Miller \& Votruba-Drzal, 2013; Bailey, Jensen \& Ransom, 2014). Employment, in a developing country like Bangladesh, provides a critical link between economic growth and poverty alleviation as the vast majority of the people depends on employment as their only source of livelihood (Rahman, Titumir \& Nasrin, 2018). Comparing to rural areas, this employment opportunity is higher in urban areas. All these differentiations have a pushing effect independent of socioeconomic and demographic factors that drive many rural residents to migrate to cities, to pursue both expected socio-economic gains.

However, rural areas have witnessed significant social change, particularly from the effects of migration resulting in changing population structures. This change in population structure is very challenging issue not only for the urban dwellers but also for the country as a whole. In order to balance development of the country, the gap between rural-urban opportunities need to be addressed. In doing so, research on rural-urban inequalities is essentially needed. Thus, an attempt is made in this study to gain a better understanding on rural-urban differentiations in selected socio-demographic characteristics of Bangladesh's population.

\section{Materials and Methods}

This paper is based on the data mainly collected from the Report on Bangladesh Sample Vital Statistics (SVRS) of different years published by Bangladesh Bureau of Statistics (BBS). Different statistical reports, relevant research papers, books and many national and international journals have also been reviewed for conducting this study. We have used (i) arithmetic growth model to calculate required rate of increase or decrease of different socio-demographic variables; and (ii) Karl Pearson coefficient of correlation to estimate the degree of linear relationship between two variables.

The arithmetic growth rate can be calculated by using the following mathematical equation:

$P_{l}=P_{b}(1+r y)$

$\Rightarrow \quad r=\frac{1}{y}\left(\frac{P_{l}}{P_{b}}-1\right)$

Where,

$P_{l}=$ Value of the launch year;

$P_{b}=$ Value of the base year;

$\mathrm{y}=$ Number of years between launch year and base year;

$\mathrm{r}=$ Rate of growth

While Karl Pearson coefficient of correlation is estimated as:

$r(X, Y)=\frac{\frac{1}{n} \Sigma X Y-\bar{X} \bar{Y}}{\sqrt{\left(\frac{1}{n} \Sigma X^{2}-\bar{X}^{2}\right)\left(\frac{1}{n} \Sigma Y^{2}-\bar{Y}^{2}\right)}}$

Where,

$\mathrm{X}$ and $\mathrm{Y}$ are two variables; and

$r(X, Y)=$ Coefficient of correlation between $X$ and $Y$.

\section{Results and Discussion}

\subsection{Adult literacy rate}

Bangladesh has made some considerable progresses in education sector over the last few decades. It is expected that, the progresses in education sector will faster than the current if there are no spatial differences. Along with other factors, adult literacy is one of the most influential developmental factors. 
Adult literacy rate is the percentage of population of age 15 years and over who can write a letter to the total population of the same age group. The adult literacy has increased from 61 percent in 2013 to about 73 percent in 2017 with an increase rate of 4.83 percent per year for the total population. In rural areas, this adult literacy has increased from 57 percent in 2013 to 66 percent in 2017 with an annual increase rate of 3.99 percent while in urban areas, this rate has increase annually by 2.36 percent during the same period (i.e. 2013-2017). However, the rate of increase is higher in rural areas than the urban. The overall percentage of adult literacy is considerable higher in urban areas than rural. This inequality in adult literacy rate might be responsible to pin down the overall development of the country. Figure 1 also demonstrates the year-wise rate of increasing adult literacy during the last five years (2013-2017) for total, rural and urban areas.

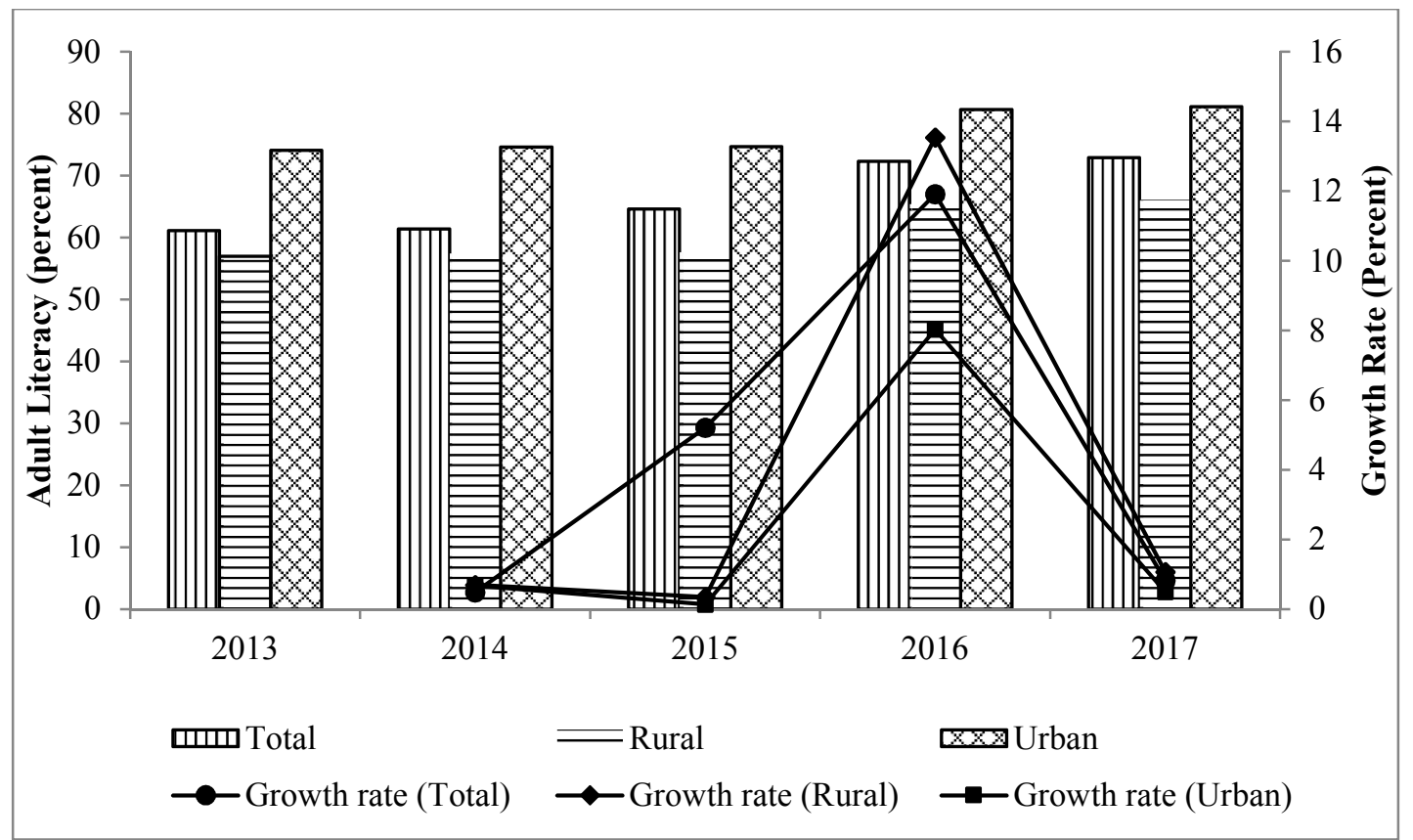

Fig. 1: Rural-urban differentiation and annual growth rate of adult literacy

Note: Authors' calculation based on the Report on Bangladesh Sample Vital Statistics (SVRS) 2017, Bangladesh Bureau of Statistics (BBS) 2018.

\subsection{Dependency ratio}

Dependency ratio can also be considered as one of the development measures that reflects the status of the society. Dependency ratio is defined as the ratio of sum of population aged 0-14 years and $65+$ years to the working age population (i.e. the population aged 15-64 years) expressed as percentage. The dependency ratio for the total population has decreased from 58 percent in 2013 to 53 percent in 2017 with an annual decreased rate of 2.2 percent. This ratio has decreased slowly both for rural and urban areas and the annual rate of decrease was 1.63 percent and 1.5 percent respectively between 2013 and 2017. It is found that dependency ratio is higher in rural areas than their counterparts (Figure 2). Figure 2 also demonstrates year-wise dependency rate of decreasing tendency for total population in rural and urban areas.

\subsection{Age at first marriage}

Age at first marriage for females in a society is also influenced by their socio-cultural status and environmental situation in which they live (Goni and Rahman, 2012). Poverty is one of the major factors under-pining early marriages (Nasrin and Rahman, 2012). It is found that the mean age at first marriage in recent times especially of males by and large has gone down marginally. For example, the age at first marriage as computed in 2015 was 25.3 years, which decreased to 25.2 years in 2016 and further to 25.1 year in 2017. Female age at first marriage remained static (18.4 years) since 2013 with a minor depression in 2014 (18.3 years). The mean age at first marriage for male has increased slowly at 0.82 
percent, 0.41 percent and 1.63 percent for total in rural and urban areas respectively during the period of 2013 to 2017. The mean age at first marriage for female was unchanged for whole country while decreased by 0.41 percent in rural areas and slightly increased by 1.06 percent in urban areas between the period 2013 and 2017 (Table 1).

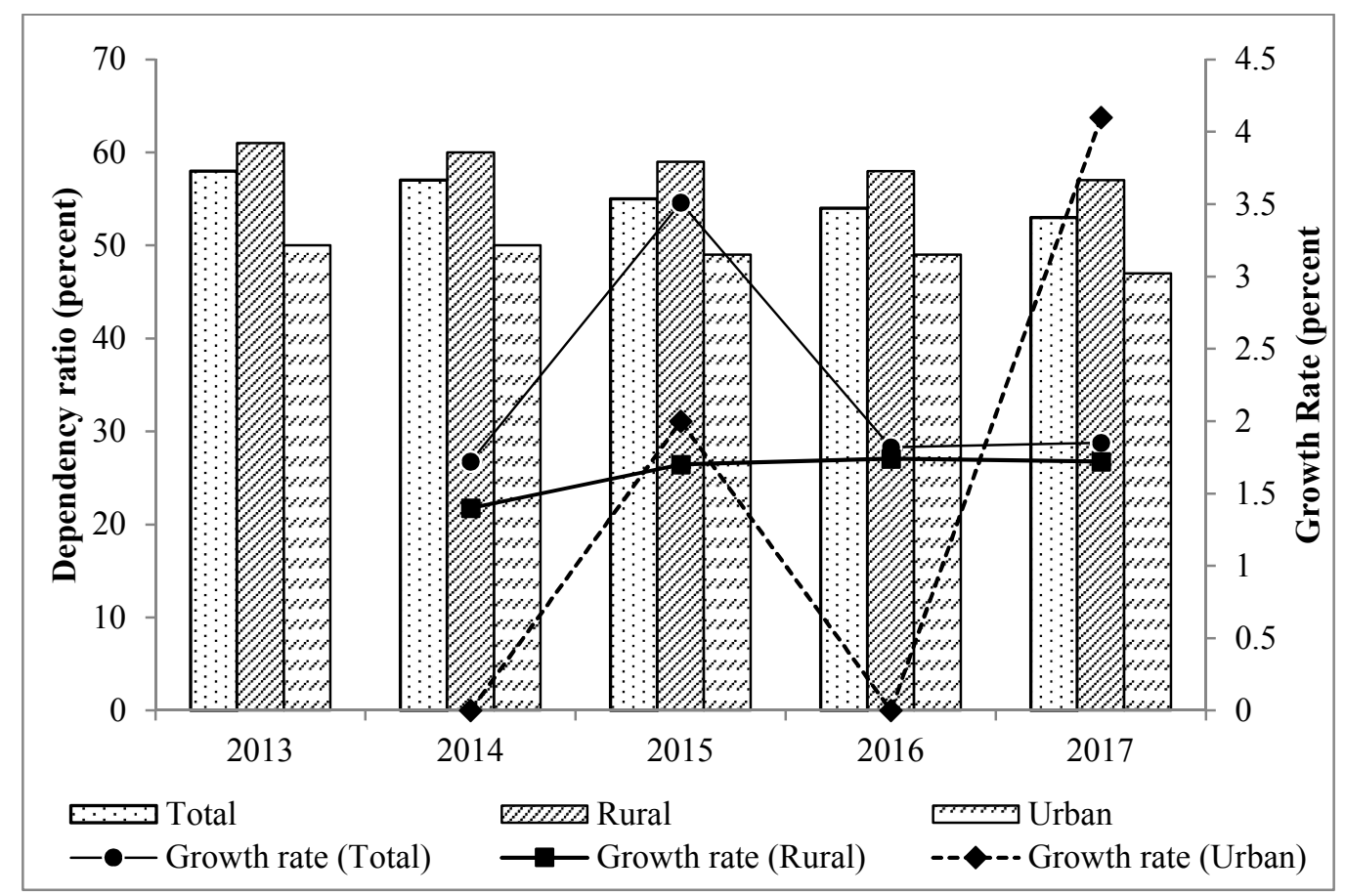

Fig. 2: Rural-urban differentiation and annual growth rate of dependency ratio

Note: Authors' calculation based on the Report on Bangladesh Sample Vital Statistics (SVRS) 2017, Bangladesh Bureau of Statistics (BBS) 2018.

Table 1: Rural-urban differentiation and annual growth rate of mean age at first marriage by sex

\begin{tabular}{|c|c|c|c|c|c|c|}
\hline Year & Total & $\begin{array}{l}\text { Growth rate } \\
\text { (Total) }\end{array}$ & Rural & $\begin{array}{l}\text { Growth rate } \\
\text { (Rural) }\end{array}$ & Urban & $\begin{array}{c}\text { Growth rate } \\
\text { (Urban) }\end{array}$ \\
\hline \multicolumn{7}{|c|}{ Mean age at first marriage (male) } \\
\hline 2013 & 24.3 & & 24.1 & - & 24.6 & - \\
\hline 2014 & 24.9 & 2.47 & 24.7 & 2.49 & 26.4 & 7.32 \\
\hline 2015 & 25.3 & 1.61 & 24.8 & 0.40 & 26.4 & 0.00 \\
\hline 2016 & 25.2 & -0.40 & 24.7 & -0.40 & 26.3 & -0.38 \\
\hline 2017 & 25.1 & -0.40 & 24.5 & -0.81 & 26.2 & -0.38 \\
\hline $\mathbf{r}_{2013-2017}$ & \multicolumn{2}{|c|}{0.82} & \multicolumn{2}{|c|}{0.41} & \multicolumn{2}{|c|}{1.63} \\
\hline & \multicolumn{6}{|c|}{ Mean age at first marriage (female) } \\
\hline 2013 & 18.4 & - & 18.2 & - & 18.9 & - \\
\hline 2014 & 18.3 & -0.54 & 18.1 & -0.55 & 19.4 & 2.65 \\
\hline 2015 & 18.4 & 0.54 & 18.0 & -0.55 & 19.4 & 0.00 \\
\hline 2016 & 18.4 & 0.00 & 17.9 & -0.56 & 19.6 & 1.03 \\
\hline 2017 & 18.4 & 0.00 & 17.9 & 0.00 & 19.7 & 0.51 \\
\hline $\mathbf{r}_{2013-2017}$ & \multicolumn{2}{|c|}{0.00} & \multicolumn{2}{|c|}{-0.41} & \multicolumn{2}{|c|}{1.06} \\
\hline
\end{tabular}

Note: Authors' calculation based on the Report on Bangladesh Sample Vital Statistics (SVRS) 2017, Bangladesh Bureau of Statistics (BBS) 2018.

\subsection{Contraceptive prevalence rate}

Contraceptive prevalence rate is very important to control the population of a country that can be defined as the percentage of couple currently practicing any contraceptive method to number of currently married women of reproductive age. As a populous country, Bangladesh needs to increase this rate. But over the last five years (i.e. 2013-2017), this rate has slightly increased (almost static) for total ( 0.04 percent) and urban areas ( 0.86 percent) while decreased in rural areas ( -0.97 percent). It is 
found that the contraceptive prevalence rate was decreased in most of the cases during 2013-2017 except urban areas where this rate has slightly increased (Figure 3).

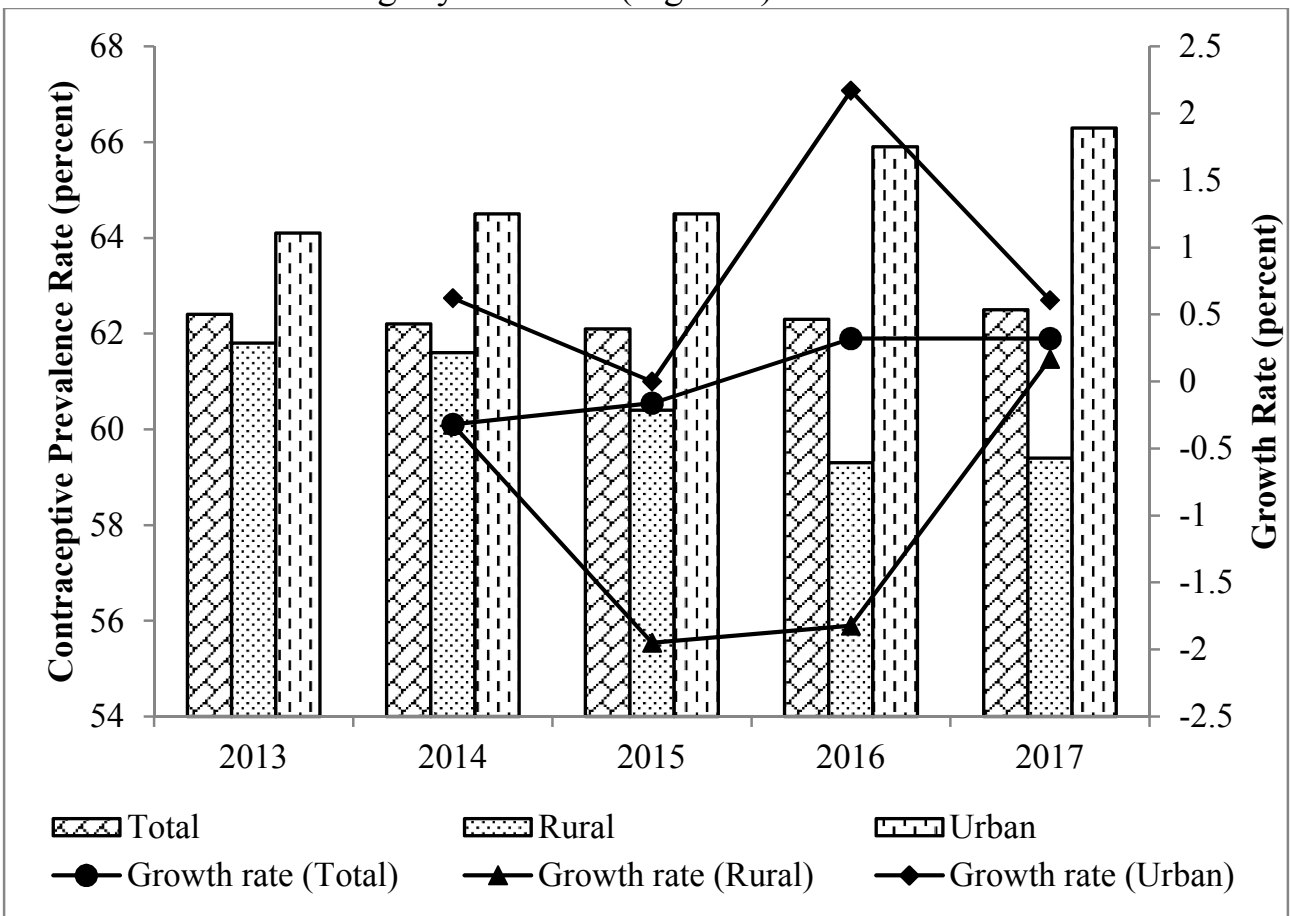

Fig. 3: Rural-urban differentiation and annual growth rate of contraceptive prevalence rate

Note: Authors' calculation based on the Report on Bangladesh Sample Vital Statistics (SVRS) 2017, Bangladesh Bureau of Statistics (BBS) 2018.

\subsection{Fertility and mortality}

Crude death rate is considered as one of the easiest fertility measures. In previous analysis, it is found that the rate of contraceptive prevalence remains almost fixed over the last few years. This has reflected in the analysis of fertility. The crude birth rate has slightly decreased $(0.66 \%)$ in the country during 2013-2017 while increased annually by 1.42 percent at rural areas during the same period. The crude death rate has annually decreased by 2.88 percent at the urban areas at the same time period (Table 2). Like crude birth rate, total fertility rate has also decreased for the whole country and urban areas while increased in rural areas. The total fertility rate of the country has decreased by 0.71 percent annually from 2.11 in 2013 to 2.05 in 2017 while in urban areas the total fertility has decreased by 2.17 percent per year during the same time period. Instead, the total fertility rate in rural areas has increased from 2.19 in 2013 to 2.37 in 2017 with an annual increase rate of 2.05 percent (Table 2).

To explain the mortality situation of a country, crude death rate is the most important and simple measure. The crude death rate has slightly decreased from 5.3 in 2013 to 5.1 in 2017 with a rate of 0.94 percent per annum for the total population. This decreased rate was 2.17 percent in urban areas during same time period. In rural areas, this crude death rate has increased to 5.7 percent in 2017 from 5.6 in 2013 with an annual increase rate of 0.44 percent (Table 2).

\subsection{Degree of association between adult literacy rate and selected demographic variables}

In this section, we have presented the degree of association between adult literacy rate and selected demographic characteristics of the population over the last five years (i.e. 2013-2014). It is found that, adult literacy rate has strong negative correlation with the dependency ratio of the population $(\mathrm{r}=-0.94)$. A moderate positive correlation was found between adult literacy rate and mean age at first marriage both for male $(\mathrm{r}=0.60)$ and female $(\mathrm{r}=0.49)$. Contraceptive prevalence rate also positively correlated with adult literacy rate and their coefficient is estimated at 0.45 . Education of population has largely associated on fertility and mortality. Analysis reveals that, adult literacy rate has stronger negative effect on crude birth rate $(\mathrm{r}=-0.92)$, also with total fertility rate and crude death rate and their coefficient is calculated at -0.74 and -0.76 respectively (Figure 4 ). 
Table 2: Rural-urban differentiation and annual growth rate of fertility and mortality

\begin{tabular}{|c|c|c|c|c|c|c|}
\hline Year & Total & $\begin{array}{l}\text { Growth rate } \\
\text { (Total) }\end{array}$ & Rural & $\begin{array}{c}\text { Growth rate } \\
\text { (Rural) }\end{array}$ & Urban & $\begin{array}{c}\text { Growth rate } \\
\text { (Urban) }\end{array}$ \\
\hline & \multicolumn{6}{|c|}{ Crude birth rate (per 1000 population) } \\
\hline 2013 & 19.0 & - & 19.3 & - & 18.2 & - \\
\hline 2014 & 18.9 & -0.53 & 19.4 & 0.52 & 17.2 & -5.49 \\
\hline 2015 & 18.8 & -0.53 & 20.3 & 4.64 & 16.5 & -4.10 \\
\hline 2016 & 18.7 & -0.53 & 20.9 & 2.96 & 16.1 & -2.42 \\
\hline 2017 & 18.5 & -1.10 & 20.4 & -2.40 & 16.1 & 0.00 \\
\hline \multirow[t]{2}{*}{$\mathbf{r}_{2013-2017}$} & \multicolumn{2}{|c|}{-0.66} & \multicolumn{2}{|c|}{1.42} & \multicolumn{2}{|r|}{-2.88} \\
\hline & \multicolumn{6}{|c|}{ Total fertility rate (per women aged $15-49$ years) } \\
\hline 2013 & 2.11 & & 2.19 & & 1.84 & \\
\hline 2014 & 2.11 & 0.00 & 2.22 & 1.37 & 1.77 & -3.80 \\
\hline 2015 & 2.10 & -0.47 & 2.30 & 3.60 & 1.72 & -2.82 \\
\hline 2016 & 2.10 & 0.00 & 2.38 & 3.48 & 1.68 & -2.33 \\
\hline 2017 & 2.05 & -2.38 & 2.37 & -0.42 & 1.68 & 0.00 \\
\hline \multirow[t]{2}{*}{$\mathbf{r}_{2013-2017}$} & \multicolumn{2}{|c|}{-0.71} & \multicolumn{2}{|c|}{2.05} & \multicolumn{2}{|r|}{-2.17} \\
\hline & \multicolumn{6}{|c|}{ Crude death rate (per 1000 population) } \\
\hline 2013 & 5.3 & - & 5.6 & - & 4.6 & - \\
\hline 2014 & 5.2 & -1.89 & 5.6 & 0.00 & 4.1 & -10.87 \\
\hline 2015 & 5.1 & -1.92 & 5.5 & -1.79 & 4.6 & 12.19 \\
\hline 2016 & 5.1 & 0.00 & 5.7 & 3.64 & 4.2 & -8.70 \\
\hline 2017 & 5.1 & 0.00 & 5.7 & 0.00 & 4.2 & 0.00 \\
\hline $\mathbf{r}_{2013-2017}$ & \multicolumn{2}{|c|}{-0.94} & \multicolumn{2}{|c|}{0.44} & \multicolumn{2}{|r|}{-2.17} \\
\hline
\end{tabular}

Note: Authors' calculation based on the Report on Bangladesh Sample Vital Statistics (SVRS) 2017, Bangladesh Bureau of Statistics (BBS) 2018.

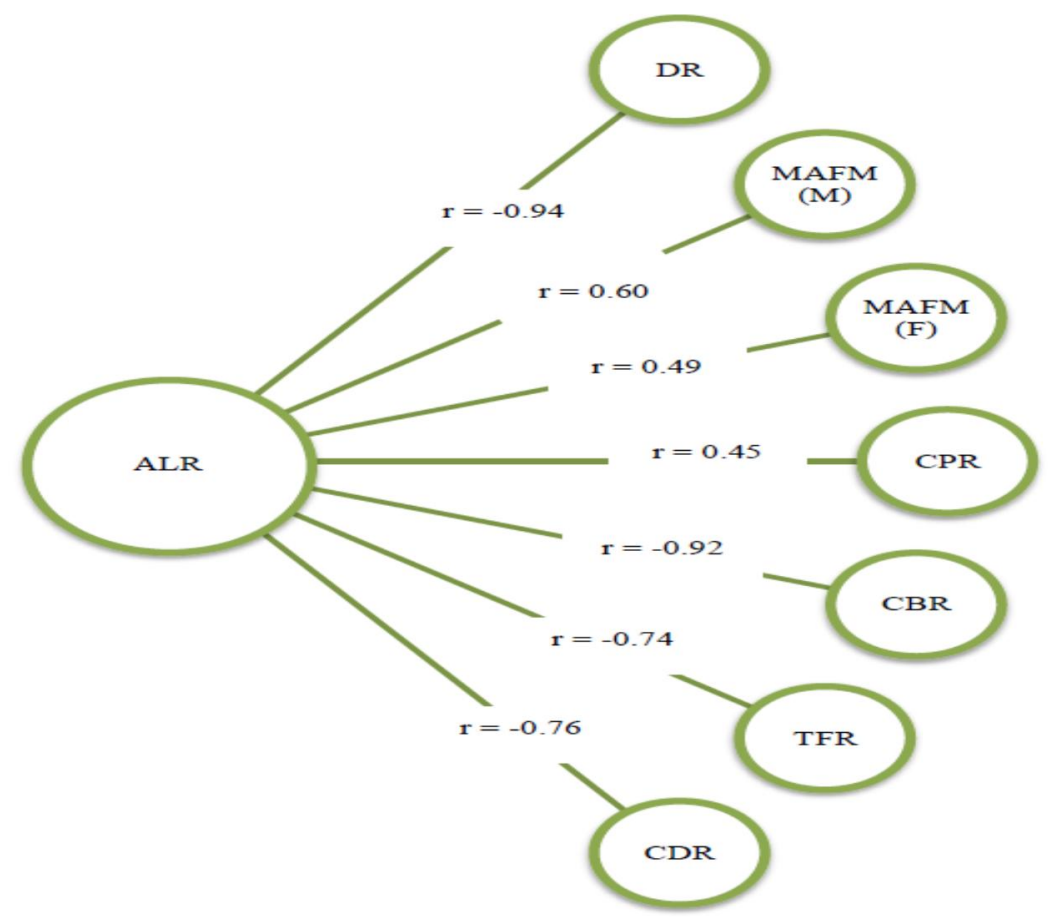

Fig. 4: Degree of association between adult literacy rate and selected demographic variables

Note: Authors' calculation based on the Report on Bangladesh Sample Vital Statistics (SVRS) 2017,Bangladesh Bureau of Statistics (BBS) 2018.

ALR = Adult Literacy Rate; DR = Dependency Ratio; MAFM (M) = Mean Age at First Marriage (Male); MAFM $(\mathrm{F})=$ Mean Age at First Marriage (Female); CPR $=$ Contraceptive Prevalence Rate; $\mathbf{C B R}=$ Crude Birth Rate; $\mathbf{T F R}=$ Total Fertility Rate; and $\mathbf{C D R}=$ Crude Death Rate 


\section{Conclusion and Recommendations}

Despite quantitative progress in socioeconomic and demographic fronts, the country needs to travel a long way to address spatial inequality and ensure a better life for all the population of the country as well as to ensure the desired development of the country. Bangladesh has already achieved some targets in the context of millennium development goals (MDGs) and strongly committed to achieve the target of sustainable development goals (SDGs). Rural-urban inequality will be the most crucial factor that might have negative impact in reaching such development targets. Analysis of this paper indicates that there is a progress in various socio-demographic characteristics since independence of the country but the progress is quite slow in the recent years. There is always a difference in the progresses of these socio-demographic sectors between rural and urban areas. In most of the cases, the progresses are strongly took place in the urban side rather that their rural counterparts. Study showed that the fertility and mortality has decreased over the last five years in urban areas while increased in rural areas. By considering the degree of association, the study showed that the adult literacy rate is strongly correlated with some selected demographic characteristics.

This paper aims to highlight a striking feature of rural-urban differentiations of selected sociodemographic backdrops in Bangladesh. The results of this paper might be useful enough in formulating effective policies and programmes along with perfect implementation of such programmes in addressing rural-urban differentials of the developing countries as well as Bangladesh.It must be frazzled that any plan and programme to improve the urban circumstance must correspond with plan and programme to improve the rural areas in order to stamp out the commonness of the rural-urban inequality. It is needed to improve the rural drift, tackling the issues of sustainable development and infrastructural distributions are crucial. Without ensuring a balanced development between rural and urban areas, the required development of Bangladesh will remain elusive. Theoretically some of the strategic documents and policy papers are sound and seems to be implementable, but in reality, the outcomes are yet to be discernible. The government needs to be creative in renewing and revising strategies and approaches for implementation, responding to the current challenges by not only resorting to previous inappropriate policies. Unless measures are taken to address the rural-urban inequality, it will continue to be a major obstacle to the achievement of expected development of Bangladesh.

\section{References}

Agrawal, T. 2014. Educational inequality in rural and urban India. International Journal of Educational Development, 34, 11-19.

Bailey, C., J. Leif, and E. Ransom, 2014. "Rural America in a Globalizing World: Introduction and Overview in Bailey, C., Leif, J., and Ransom, E. (eds.). Rural America in a Globalizing World: Problems and Prospects for the 2010s. West Virginia University Press.

Bangladesh Bureau of Statistics (BBS), 2015. Population Distribution and Internal Migration in Bnagladesh, Population Monograph, Volume-6. Dhaka Bangladesh

Bangladesh Bureau of Statistics (BBS), 2018. Report on Bangladesh Sample Vital Statistics (SVRS) 2017. Statistics and Informatics Division (SID), Ministry of Planning Government of the People's Republic of Bangladesh. Dhaka, Bangladesh

Byun, S.Y., J. Meece, and M. Irvin, 2012. Rural-nonrural disparities in postsecondary education attainment revisited. American Educational Research Journal, 49(3), 412-437.

Chankseliani, M., 2013. Rural Disadvantage in Georgian Higher Education Admissions: A MixedMethods Study. Comparative Education Review, 57(3), 224-256.

Giroux, S., F. Jah, and P. Eloundou-Enyegue, 2010. in Schafft, K.A. and A. Youngblood Jackson (Eds.). "Globalization, asymmetric urbanization, and rural disadvantage in Sub-Saharan Africa" in Rural Education for the Twenty-First Century: Identity, Place, and Community in a Globalizing World. University Park, Pennsylvania: The Pennsylvania State University Press.

Goni, M.A. and K.M.M. Rahman, 2012. Age at First Marriage in Bangladesh: Socio-economic Differentials and Determinants. Middle East Journal of Age and Ageing, 9 (3): 28-34.

Heyns, B., 2005. Emerging inequalities in Central and Eastern Europe. Annual Review of Sociology, 31(1), 163-197. 
Iannelli, C., 2002. Parental education and young people's educational and labour market Outcomes: A comparison across Europe. (Working paper). Mannheimer Zentrumfür Europäische Sozialforschung: 45.

Koricick, A., 2014. Proceedings from AERA 2014: The Effects of Rurality on College Access and Choice. Philadelphia, Pennsylvania.

MacTavish, K. A. and S. Salamon. 2006. Pathways of youth development in a rural trailer park. Family Relations, 55(2).

McIlveen, P., T. Morgan, and J. Bimrose, 2012. A longitudinal study of the experience of a career development program for rural school students. Australian Journal of Career Development, 21(22), 22-30.

Miller, P. and E. Votruba-Drzal, 2013. Early academic skills and childhood experiences across the ruralurban continuum. Early Childhood Research Quarterly, 28, 234-248.

Nasrin, S.O. and K.M.M. Rahman, 2012. Factors affecting early marriage and early conception of women: A case of slum areas in Rajshahi City, Bangladesh. International Journal of Sociology and Anthropology, 4 (2): 54-62.

Provasnik, S., A., M.M. Kewal-Ramani, L. Coleman, Gilbertson, W. Herring, and Q. Xie, 2007. Status of Education in Rural America. NCES 2007-040. National Center for Education Statistics.

Rahman, K.M.M., M.N. Hoque, and R.A.M. Titumir, 2016. Progress and Pitfalls of Women in Bangladesh: Structural Rigidities and Embedded Institutions. Demography India,45 (land 2): 102-116.

Rahman, K.M.M., R.A.M. Titumir and S.O Nasrin, 2018. Dimension of Women Labour Force in Bangladesh: Evidence from Nationally Representative Data. The Journal of Social Sciences Research, Academic Research Publishing Group, vol. 4(1):9-15.

Tickamyer, A.R. and C.M. Duncan, 1990. Poverty and Opportunity Structure in Rural America. Annual Review of Sociology, 16, 67-86.

Zichy, A., 2000. The status of rural development in Central and Eastern Europe. Proceedings from The Challenge of Rural Developing in the EU Accession Countries: Third World Bank/FAO EU Accession Workshop. Washington, DC: The World Bank. 